\title{
Motor cortex electric stimulation for the treatment of neuropathic pain
}

\author{
Walter J. Fagundes-Pereyra', Manoel Jacobsen Teixeira³ ${ }^{3}$ Nicolas Reyns', \\ Gustavo Touzet ${ }^{1}$, Sérgio Dantas ${ }^{1}$, Emmanuelle Laureau², Serge Blond ${ }^{1}$
}

\begin{abstract}
Objective: Motor cortex stimulation (MCS) is considered to be an effective treatment for chronic neuropathic pain. The aim of the present study was to assess the efficacy of MCS for treating neuropathic pain. Method: 27 patients with chronic neuropathic pain were operated. Electrodes were implanted with the use of an stereotactic frame. Electrophysiological evaluations (motor stimulation and somatosensory evoked potentials) were performed, with guidance by means of three-dimensional reconstruction of magnetic resonance images of the brain. 10 patients (37\%) presented central neuropathic pain (poststroke pain) and 17 others (63\%) presented peripheral neuropathic pain (brachial plexus avulsion, phantom limb pain or trigeminal pain). Results: In 15 patients (57.7\%) the pain relief was $50 \%$ or more; while in ten patients $(38.5 \%$ ), more than $60 \%$ of the original pain was relieved. No differences were found in relation to central and peripheral neuropathic pain $(p=0.90)$, pain location ( $p=0.81)$, presence of motor deficit $(p=0.28)$ and pain duration $(p=0.72)$. No major complications were observed. Conclusion: MCS was efficient for treating patients presenting chronic central or peripheral neuropathic pain.
\end{abstract}

Key words: electric motor cortex stimulation, neuropathic pain, central pain, peripheral pain, treatment.

\section{Estimulação elétrica do córtex motor no tratamento da dor neuropática}

\section{RESUMO}

Objetivo: A estimulação do córtex motor (ECM) é método considerado eficaz no tratamento da dor neuropática crônica rebelde. O presente estudo avaliou a eficácia da ECM no tratamento de pacientes portadores de dor neuropática crônica. Método: 27 doentes foram avaliados; 10 (37,0\%) apresentavam dor neuropática de origem central, enquanto 17 (63,0\%), dor neuropática periférica. Avulsão de raízes do plexo braquial, dor no membro fantasma, dor decorrente de doença cerebrovascular isquêmica ou hemorrágica ou neuropatia trigeminal foram as causas mais freqüentes da dor. Os doentes foram operados com uso da técnica de localização estereotáctica do córtex motor associadamente a estudo eletroneurofisiológico (estimulação motora e potencial evocado somatossensitivo) ou ainda com uso de imagens de ressonância magnética do encéfalo reconstruídas tridimensionalmente. Resultados: $\bigcirc$ alívio da dor foi igual ou superior a $50 \%$ em 15 doentes $(57,7 \%)$, sendo em $10(38,5 \%)$, superior a 60\%. Não houve diferença nos resultados quanto a origem central ou periférica $(p=0,90)$ da dor, localização da dor $(p=0,81)$, ocorrência ou não de déficit motor $(p=0,28)$ e duração da sintomatologia $(p=0,72)$. Não foram observadas complicações graves. Conclusão: A estimulação do córtex motor foi útil no tratamento da dor neuropática crônica rebelde tanto de origem central como periférica.

\section{Correspondence}

Walter J. Fagundes-Pereyra

Rua Walter J. Pasolini 100

29050-490 Vitória ES - Brasil

E-mail: neurowalter@hotmail.com

Received 30 March 2010

Received in final form 21 June 2010

Accepted 28 June 2010
Palavras-chave: estimulação elétrica do córtex motor, dor neuropática, dor central, dor periférica, tratamento.

'Department of Neurosurgery, Roger Salengro Hospital, University of Lille, Lille, France; ${ }^{2}$ Department of Neurophysiology, Roger Salengro Hospital, University of Lille, Lille, France; ${ }^{3}$ Department of Neurosurgery, Full Professor, São Paulo University, São Paulo SP, Brazil. 
Neuropathic pain is one of the most difficult and worst conditions to treat in clinical practice ${ }^{1,2}$. Electrical stimulation at different sites in the central nervous system has been shown to induce pain relief, and is now considered to be a viable form of therapy for chronic deafferentation pain $^{2,3}$.

In 1988, Namba and Nishimoto initially proposed motor cortex stimulation (MCS) ${ }^{4}$. In 1991, Tsubokawa et al. introduced epidural MCS as an alternative type of treatment for patients with central deafferentation pain ${ }^{5}$. These authors showed that MCS inhibited thalamic burst activity. They treated seven patients presenting thalamic pain by means of epidural MCS with satisfactory pain control in all cases, without major complications ${ }^{5}$. Meyerson et al. further extended the indications for MCS by reporting pain relief in relation to trigeminal neuropathic pain ${ }^{6}$. Following these examples, many authors have used this tech- nique to treat neuropathic pain from different origins ${ }^{7,8}$. Syndromes that have been treated by MCS include anesthesia dolorosa and other forms of trigeminal deafferentation pain, central pain secondary to stroke or spinal cord injury, postherpetic neuralgia, peripheral deafferentation pain syndromes such as plexus avulsion, sciatic nerve injury, phantom limb pain, stump pain, complex regional pain syndrome and even glossopharyngeal neuralgia ${ }^{7-10}$.

Despite an increasing number of indications and procedures over the last few years, many questions remain, concerning the mechanisms of action, indications, predictive factors, implantation strategies and further technical matters in MCS therapy ${ }^{11}$.

We report our experience from managing patients with chronic neuropathic pain that was refractory to different types of therapy in a current series of twenty-seven cases treated by means of epidural MCS.

Table 1. Demographic data on the patients.

\begin{tabular}{|c|c|c|c|c|c|c|c|c|}
\hline $\begin{array}{l}\text { Patient } \\
\text { number }\end{array}$ & Sex & $\begin{array}{c}\text { Age } \\
\text { (years) }\end{array}$ & Pain origin & $\begin{array}{c}\text { Pain } \\
\text { location }\end{array}$ & Vas & $\begin{array}{c}\text { Pain duration } \\
\text { (months) }\end{array}$ & Allodynea & $\begin{array}{l}\text { Motor } \\
\text { deficit }\end{array}$ \\
\hline 1 & $M$ & 52 & Stroke & Upper limb & 9 & 48 & Yes & Yes \\
\hline 2 & M & 37 & Brachial plexus lesion & Upper limb & 8 & 48 & None & Yes \\
\hline 3 & M & 63 & Thalamic hemorrhage & Upper limb & 8 & 60 & Yes & Yes \\
\hline 4 & M & 51 & Brain injury & Face & 10 & 72 & Yes & None \\
\hline 5 & $\mathrm{~F}$ & 62 & Brachial plexus lesion & Upper limb & 10 & 24 & None & Yes \\
\hline 6 & $M$ & 34 & Brachial plexus lesion & Upper limb & 5 & 75 & Yes & Yes \\
\hline 7 & $M$ & 59 & Multiple sclerosis & Face & 9 & 120 & None & None \\
\hline 8 & $F$ & 64 & Stroke & Upper limb & 8 & 17 & Yes & Yes \\
\hline 9 & $M$ & 40 & Brain tumor & Face & 10 & 72 & Yes & Yes \\
\hline 10 & $M$ & 28 & Brachial plexus lesion & Upper limb & 8 & 41 & None & Yes \\
\hline 11 & $M$ & 53 & Brachial plexus lesion & Upper limb & 7 & 30 & Yes & Yes \\
\hline 12 & M & 31 & Phantom limb & Upper limb & 6 & 162 & None & Amputated \\
\hline 13 & M & 45 & Brain injury & Face & 10 & 36 & Yes & None \\
\hline 14 & $M$ & 39 & Brachial plexus lesion & Upper limb & 8 & 72 & None & Yes \\
\hline 15 & $\mathrm{~F}$ & 67 & Trigeminal neuropathic pain & Face & 7 & 84 & Yes & None \\
\hline 16 & M & 38 & Brachial plexus lesion & Upper limb & 8 & 36 & Yes & Yes \\
\hline 17 & M & 33 & Brachial plexus lesion & Upper limb & 9 & 15 & None & Yes \\
\hline 18 & M & 51 & Peripheral nerve injury & Upper limb & 8 & 108 & Yes & Yes \\
\hline 19 & $M$ & 35 & Stroke & Face & 7 & 24 & Yes & None \\
\hline 20 & $\mathrm{~F}$ & 60 & Phantom limb & Lower limb & 6 & 252 & None & Amputated \\
\hline 21 & M & 41 & Brachial plexus lesion & Upper limb & 5 & 57 & None & Yes \\
\hline 22 & M & 56 & Brachial plexus lesion & Upper limb & 8 & 384 & Yes & Yes \\
\hline 23 & M & 49 & Phantom limb & Upper limb & 9 & 348 & None & Amputated \\
\hline 24 & $M$ & 66 & Thalamic hemorrhage & Upper limb & 7 & 60 & Yes & Yes \\
\hline 25 & $M$ & 31 & Brachial plexus lesion & Upper limb & 6 & 30 & Yes & Yes \\
\hline 26 & $\mathrm{~F}$ & 28 & Spine cord injury & Upper limb & 7 & 63 & Yes & None \\
\hline 27 & M & 50 & Brachial plexus lesion & Upper limb & 7 & 360 & Yes & Yes \\
\hline
\end{tabular}

VAS: visual analog scale. 


\section{METHOD}

\section{Patient population}

Twenty-seven patients with chronic central or peripheral neuropathic pain were considered eligible for MCS at Lille University Hospital Center between 1994 and 2002. A summary of the patient data is presented in Table 1. There were 22 males (81.5\%) and 5 females (18.5\%), aged 28 to 67 years (average of $46.8 \pm 12.5$ years). Ten patients (37.0\%) suffered from central neuropathic pain while 17 others (63.0\%) suffered from peripheral neuropathic pain, from different origins. The mean follow-up was 29.1 ( \pm 24.6$)$ months (ranging from 7 to 101 months).

All the patients had been treated with different medications, including anticonvulsants, antidepressants, anti-inflammatory agents and even opioid drugs, in various combinations. Four patients had previously been treated by means of drezotomy, three by means of spinal cord stimulation, eleven by means of transcutaneous electrical neurostimulation (TENS), whereas thalamic stimulation was attempted on one patient. All of these approaches failed to sufficiently alleviate the patients' pain.

Electroneurophysiological and imaging studies and psychological assessment were performed preoperatively on all the patients. Patients presenting either severe depressive or neurotic tendencies were not candidates for MCS.

\section{Pain assessment}

The pain level and characteristics of each patient were assessed by a multidisciplinary group at the Pain Clinic affiliated to our service. Each patient was asked to specify the pain intensity according to a visual analog scale (VAS) and by answering a pain questionnaire (McGill questionnaire adapted to French). The effects of stimulation were classified into four categories ${ }^{11}$ : excellent, reduction of pain level by 80 to 100\%; good, 60 to $79 \%$ reduction; fair, 40 to $59 \%$ reduction; and poor, less than $40 \%$ reduction. The effects of stimulation were evaluated at predetermined intervals. The pain was assessed regularly, at discharge from hospital and at each follow up visit (one, three and six months, and then annually). Medication intake was quantified at the same intervals described above.

Preoperatively, the patients' pain scores ranged from 5 to 10 (average of $7.8 \pm 1.5$ ), based on the VAS. The mean history of pain was 8.7 years.

\section{Surgical procedures}

In the first 15 cases of this series, the electrodes were introduced under local anesthesia into the epidural space through a burr hole, as initially described by Tsubokawa et al. ${ }^{5,12}$ in association with a Talairach stereotactic frame. The target coordinates were obtained by means of stereotactic angiography.

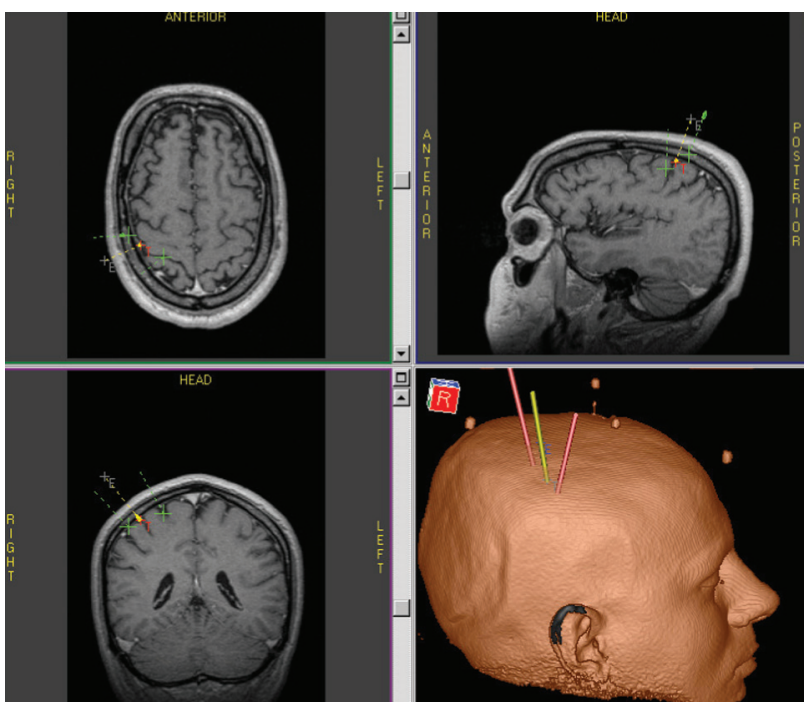

Fig 1. Magnetic resonance image (MRI) demonstrating the target site for motor cortex stimulation.

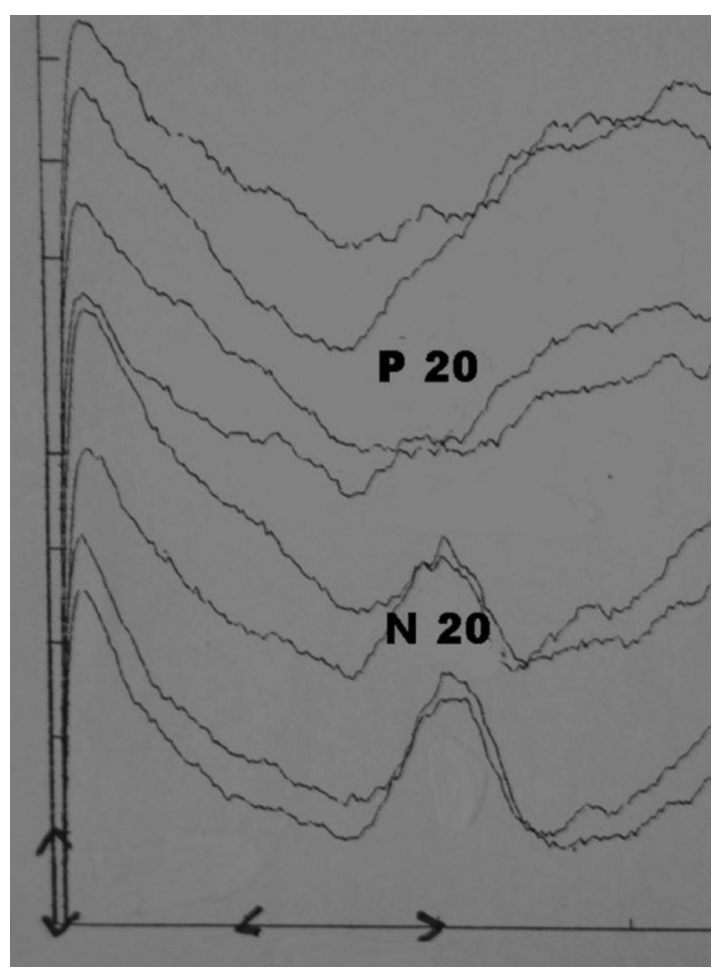

Fig 2. Perioperative somatosensory evoked potential showing a N20-P20 inversion corresponding to the central sulcus (median nerve stimulation: $3.7 \mathrm{~Hz}$; $19 \mathrm{~mA}$; active electrode poles [0, 1, 2, 3]).

In the subsequent 12 patients, after induction of general anesthesia, a rectilinear incision was performed, centered over the central sulcus, in accordance with guidance imaging (Fig 1). This was followed by rectangular craniotomy overlying the sensory-motor cortex, exposing the dura.

All the patients underwent implantation of a quadripolar stimulation lead with round $5 \mathrm{~mm}$ electrodes each 
separated by $5 \mathrm{~mm}$ (Resume ${ }^{\mathrm{Tm}}$, Medtronic, Inc., Minneapolis, Minnesota, USA). Once the appropriate location was determined based on the guidance imaging system, electrophysiological tests were performed (wave inversion N20-P20) (Fig 2) and motor evoked potentials. The four-electrode array was sutured to the overlying dura of the motor cortex with four stitches, in a perpendicular position based on central sulcus orientation, in a parietal-to-frontal orientation (Fig 3). The free electrode was connected to the extension lead, which was tunneled to a subcutaneous subclavicular pocket, to be connected to a pulse generator (Itrel ${ }^{\mathrm{TM}}$, Medtronic, Inc.), by means of a one-stage procedure.

\section{Postoperative care}

A skull radiograph was performed to confirm the position of the four-electrode array (Fig 4). We used a programmer (Medtronic, 7432) to generate and adjust the stimuli for different parameters by means of telemetry. Pairs of contacts were used for bipolar stimulation. For monopolar stimulation, one contact over the cortex became the anode (or cathode) while the opposite contact was the pulse generator.

\section{Statistical analysis}

Pearson's chi-square $\left(\chi^{2}\right)$ test was used for parametric values and Student's $t$ test for non-parametric values. The analysis was performed using the Epi-Info $2000^{\text {rim }}$ software (version 6.0, Centers for Disease Control, Atlanta, USA) and Statistica ${ }^{\mathrm{at}}$ software (version 6.0, Statsoft Inc, USA). Fisher's exact test correction was used when the values were less than five.

\section{RESULTS}

\section{Pain relief}

Among the 26 patients analyzed, pain relief greater than or equal to $50 \%$ was observed in 15 patients (57.7\%). In relation to the criteria established, 10 patients (38.5\%) achieved satisfactory relief (good or excellent). In four patients (15.3\%), gradual improvement of pain occurred over the first twelve months following the procedure, and the results became satisfactory. In five patients (19.2\%), although satisfactory initial relief was observed, the improvement gradually reduced over subsequent months (Fig 5). In one of the patients, one year after the implantation, the pulse generator was turned off; therefore, the initial pain relief was not sustained.

The difference in the mean VAS scores between the preoperative period (before MCS) and the end of the follow-up period was statistically significant $(\mathrm{p}<0.000001)$ (Table 2 and Fig 6).

In four patients, the pain control gradually increased over a period of several months, becoming satisfactory in

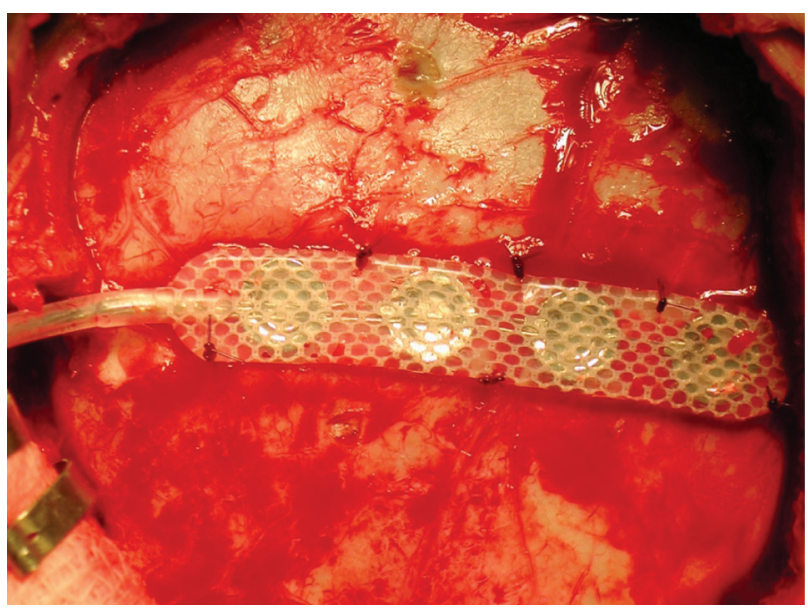

Fig 3. Perioperative image demonstrating the quadripolar electrode array fixed to the dura mater.

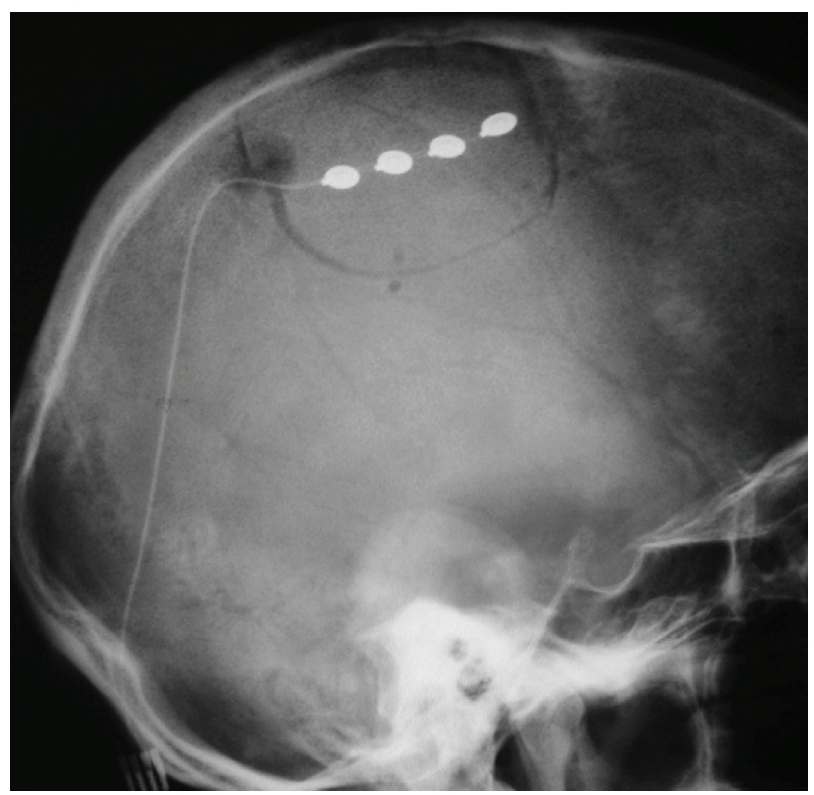

Fig 4. Postoperative cranial X-ray showing the position of the four electrodes.

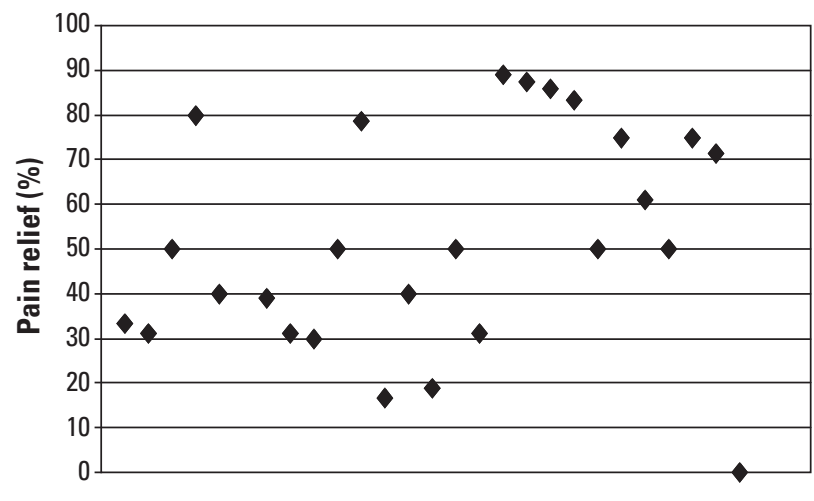

Patients distribution

Fig 5. Patient distribution according to percentage of pain relief at the end of the follow-up period, corresponding to the sequence presented in Table 1 
some of them. However, in five patients, pain control was initially achieved, but the effect progressively faded away over a period of several months and, in some of them, the pain control became unsatisfactory.

One patient did not benefit from MCS, and the pulse generator was stopped after one year. Surprisingly, one patient showed an improvement in associated hand dystonia.

No differences in relation to age $(\mathrm{p}=0.71)$, gender $(p=0.69)$, origin of the lesions (central or peripheral) $(\mathrm{p}=0.90)$, area of the pain $(\mathrm{p}=0.81)$, presence of motor deficit $(\mathrm{p}=0.28)$ or duration of pain $(\mathrm{p}=0.72)$ were observed between the patients with satisfactory pain control and the patients without such control.

In 11 patients (42.3\%), a reduction in the amount of analgesic medication intake was possible.

\section{Stimulation parameters}

Stimulation was performed at a pulse width of 45 to $60 \mu$ s initially, reaching a maximum of 60 to $210 \mu$ s at the end. The frequency ranged from 45 to $60 \mathrm{~Hz}$ initially, and was from 45 to $130 \mathrm{~Hz}$ at the last follow-up assessment. The amplitude initially ranged from 2 to $4 \mathrm{~V}(2.9 \pm 0.57)$, and was from 2 to $5.3 \mathrm{~V}(4 \pm 0.8)$ at the end. Monopolar stimulation was used for 7 patients (26.9\%), and bipolar stimulation was used for 19 (73.1\%). The active electrodes were defined by perioperative neurophysiological evaluations and were adapted postoperatively in accordance with the patient's response. Bipolar stimulation was used with the negative pole overlying the motor cortex and the positive pole over the sensory cortex ${ }^{13}$. The stimulation mode was variable, in accordance with the patient's response, and could even change for the same patient several times.

\section{Morbidity}

Stimulation at high amplitude levels during in-patient titration resulted in focal epileptic seizures in two patients. One patient developed scar dehiscence after pulse generator replacement, because of battery arrest. In two patients, infection of the stimulator pocket was observed, and in one of them, the pulse generator was removed and a new one was implanted in the opposite side. In the second case, antibiotic therapy was sufficient and no replacement was necessary.

\section{DISCUSSION}

The $46.1 \%$ of the patients with more than $50 \%$ pain relief and the $69.2 \%$ with more than $40 \%$ pain relief observed in this study are similar to the rates obtained in other studies ${ }^{1,14,15}$, which observed that $50 \%$ of the patients treated with MSC had over 50\% pain relief. In a critical review of the literature, Fontaine et al. noticed that a good
Table 2. Long-term results among patients with motor cortex stimulation, comparing the preoperative VAS score and the postoperative VAS score at the last follow-up assessment.

\begin{tabular}{lcccc}
\hline & Mean VAS score & SD & $\mathrm{t}$ & $\mathrm{p}$ \\
\hline Preoperative & 7.88 & 1.45 & 10.41 & \\
Postoperative & 3.82 & 2.15 & & $<0.000001$ \\
\hline
\end{tabular}

VAS: visual analog scale.

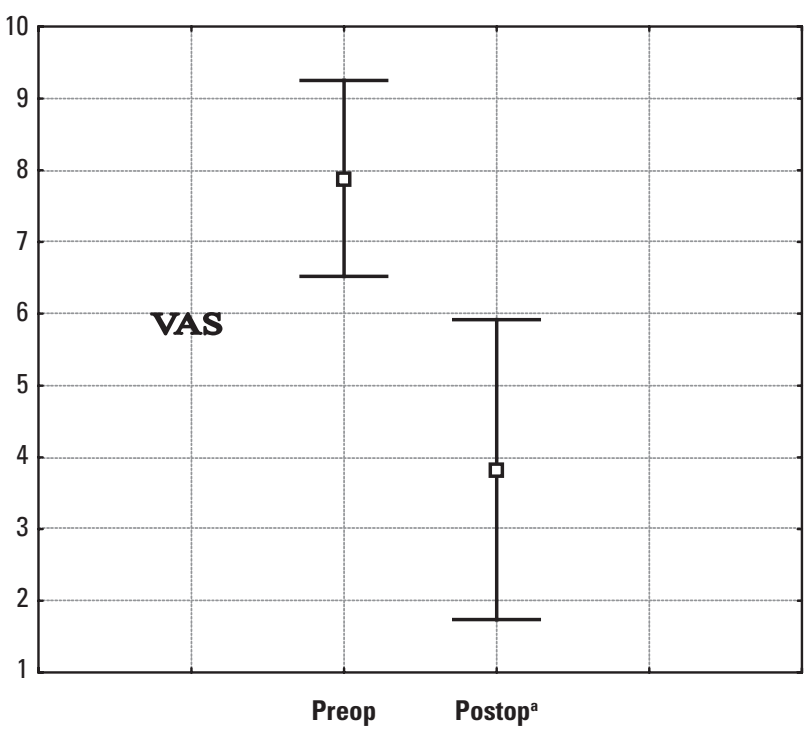

Fig 6. Long-term results among patients with motor cortex stimulation, comparing the preoperative visual analog scale (VAS) score (preop) and the postoperative VAS score at the end of the followup period (postop) ${ }^{a}(p<0.000001)$.

response to MCS (pain relief $\geq 40-50 \%$ ) was observed in around $55 \%$ of the patients who underwent surgery, and in $45 \%$ of the 152 patients with a postoperative follow-up $\geq 1$ year ${ }^{16}$. Carroll et al. reported that this rate was encouraging in this difficult group of patients, who have usually failed to respond to other types of treatment ${ }^{2}$.

If the three-category classification used by Nguyen et al. ${ }^{17}$ and Lefaucher et al. ${ }^{18}$ (good; VAS score reduction by 70-100\%; satisfactory: reduction by $40-69 \%$; and poor: reduction by $<40 \%$ ) had been applied to our data, we would have observed that $69.2 \%$ of the results were good and satisfactory.

In another review, Smith et al. showed that a positive response was achieved in 44 to $100 \%$ of MCS-treated patients ${ }^{1}$.

It seems relevant to point out that some patients who were not considered to have a satisfactory response, i.e. among whom the pain relief was only $30-40 \%$, were intolerant of MCS interruption. This denotes that even if the response is far from what would be desirable, it should 
not be disregarded in this particular group of patients suffering from a terrible type of pain, among whom almost all the current therapies had previously been attempted without success. Considering these rates in association with other types of therapy, if an intolerable pain can be transformed into an acceptable pain, this may be significant for the patient's quality of life.

In the beginning of this series, we performed electrode placement through a burr hole. However, as suggested by some authors ${ }^{15,19}$, we decided to perform craniotomy. The use of craniotomy allows for more extensive electroneurophysiological exploration. Electrode introduction through a burr hole limits the exploration ${ }^{13}$. For these reasons, we opted for craniotomy for the last 12 cases of the present series. Another refinement to our technique was the introduction of the guidance imaging system. Accurate localization of the motor cortex and precise electrode placement according to the painful areas are essential in obtaining good results ${ }^{20}$.

Predicting pain relief from MCS is a major clinical problem ${ }^{1}$. Barbiturate sensitivity and opioid insensitivity have been suggested as possible predictors of the response $^{12,21,22}$. Transcranial magnetic stimulation may be another useful tool for this purpose ${ }^{23}$. The motor response in the painful area may also be useful. However, as pointed out by Smith et al. ${ }^{1}$, the results from such tests are not a guarantee of a successful outcome. Therefore, we did not routinely perform any prediction-specific assessments.

Although an intact somatosensory system is not essential for successful treatment, the presence of an intact corticospinal tract with muscle twitching has been considered to be a prior requirement for sufficient analgesia in the respective areas of stimulation ${ }^{7}$. Katayama et al. ${ }^{14}$ observed that pain relief was satisfactory in $73 \%$ of the patients with mild or absent motor weakness. When motor weakness was present, ranging from moderate to severe, only $15 \%$ of the 13 patients benefited therapeutically from it. When motor contractions could not be induced, pain relief was achieved in only $9 \%$ of the patients. Despite these reports, the motor response could not be obtained in 11 patients with plexus avulsion in our series but, nevertheless, excellent or good pain relief was observed in three of them (27.3\%).

We observed a decrease in the effect from MCS in some patients after long-term follow-ups, just as other centers have done ${ }^{5,19}$. Tsubokawa et al. ${ }^{12}$ showed that a tissue reaction in the dura may increase the impedance of the stimulation site. Sudden increases in pain have always either been associated with lead fractures or been provoked by the fact that the pulse generator was switched off ${ }^{2}$.

Surgery-related epidural hematoma, subdural effusion, infection and dehiscence of the stimulator pocket have been reported. Other effects directly attributed to MCS have included epileptic seizures, aphasia, dysphasia, upper extremity fatigue, burning sensations in the area of stimulation, feeling of a supernumerary arm and even dystonia $^{1,6,15,17,19}$. Chronic seizures following MCS have not been observed ${ }^{8,24}$.

In one patient in our series, hand dystonia improvement was observed, as was also observed by Franzini et al. ${ }^{25}$.

Postoperative titration of stimulation parameters should be performed for each individual patient, since the response is usually variable ${ }^{26}$. Different stimulation patterns were attempted until adequate pain relief was achieved but, unfortunately, in some cases no satisfactory pain control was observed.

MCS is a non-destructive therapeutic technique and should be considered before undertaking central neuroablative procedures, when treating chronic neuropathic pain ${ }^{26}$.

In conclusion, MCS is a non-destructive, adjustable and reversible therapeutic technique that is efficient for treating patients presenting chronic central or peripheral neuropathic pain syndromes that are refractory to other types of treatment, even though its mechanisms of effect are still not well established.

ACKNOWLEDGEMENTS - We thank the staff of the Pain Unit of the Department of Neurosurgery, Roger Salengro Hospital of Lille University, for clinical support.

\section{REFERENCES}

1. Smith H, Joint C, Schlugman D, Nandi D, Stein JF, Aziz TZ. Motor cortex stimulation for neuropathic pain. Neurosurg Focus 2001;11:1-9.

2. Carrol D, Joint C, Maartens N, Shlugman D, Stein J, Aziz TZ. Motor cortex stimulation for chronic neuropathic pain: a preliminary study of 10 cases. Pain 2000;84:431-437.

3. Lima MC, Fregni F. Motor cortex stimulation for chronic pain: systematic review and meta-analysis of the literature. Neurology 2008;70:2329-2337.

4. Namba S, Nishimoto A. Stimulation of internal capsule, thalamic sensory nucleus (VPM) and cerebral cortex inhibited deafferentation hyperactivity provoked after Gasserian ganglionectomy in cat. Acta Neurochir 1988;42 (Suppl):S243-S247.

5. Tsubokawa T, Katayama Y, Yamamoto T, Hirayama T, Koyama S. Chronic motor cortex stimulation of the treatment of central pain. Acta Neurochir 1991;52:137-139.

6. Meyerson BA, Lindblom U, Linderoth B, et al. Motor cortex as treatment of trigeminal neuropathic pain. Acta Neurochir 1993;58 (Suppl):S150-S153.

7. Rainov NG, Fels C, Heidecke V, Burkert W. Epidural electrical stimulation of the motor cortex in patients with facial neuralgia. Clin Neurol Neurosurg 1997;99:205-209.

8. Brown JA. Motor cortex stimulation. Neurosurg Focus 2001;11:1-5

9. Cruccu G, Aziz TZ, Garcia-Larrea L, et al. EFNS guidelines on neurostimulation therapy for neuropathic pain. Eur J Neurol 2007;14:952-970.

10. Velasco F, Carrillo-Ruiz JD, Castro G, et al. Motor cortex electrical stimulation applied to patients with complex regional pain syndrome. Pain 2009; 147:91-98.

11. Saitoh Y, Shibata M, Hirano SI, Hirata M, Mashimo T, Yoshimine T. Motor cortex stimulation for central peripheral deafferentation. J Neurosurg 2000; 92:150-155.

12. Tsubokawa T, Katayama Y, Yamamoto T, Hirayama T, Koyama S. Chronic motor cortex stimulation in patients with thalamic pain. J Neurosurg 1993; 78:393-401. 
13. Nguyen JP, Lefaucheur JP, Le Guerinel C, et al. Motor cortex stimulation in the treatment of central and neuropathic pain. Arch Med Research 2000; 31:263-265.

14. Katayama Y, Fukaya C, Yamamoto T. Poststroke pain control by chronic motor cortex stimulation: neurological characteristics predicting a favorable response. J Neurosurg 1998;89:585-591.

15. Peyron R, Garcia-Larrea L, Deiber MP, et al. Electrical stimulation of precentral cortical area in the treatment of central pain: electrophysiological and PET study. Pain 1995;62:275-286.

16. Fontaine D, Hamani C, Lozano A. Efficacy and safety of motor cortex stimulation for chronic neuropathic pain: critical review of the literature. J Neurosurg 2009;110;251-256.

17. Nguyen JP, Lefaucheur JP, Decq P, et al. Chronic motor cortex stimulation in the treatment of central and neuropathic pain: correlation between clinical, eletrophysiological and anatomical data. Pain 1999;82:245-251.

18. Lefaucheur JP, Drouot $X$, Cunin $P$, et al. Motor cortex stimulation for the treatment of refractory peripheral neuropathic pain. Brain 2009;132: 1463-1471.

19. Elbe $H$, Rust D, Tronnier V, et al. Chronic precentral stimulation in trigeminal neuropathic pain. Acta Neurochir 1996;138:1300-1306.
20. Velasco F, Argüelles C, Carrillo-Ruiz JD, et al. Efficacy of motor cortex stimulation in the treatment of neuropathic pain: a randomized double-blind trial. J Neurosurg 2008;108;698-706

21. Canavero S, Bonicalzi V, Castellano G, Perozzo P, Mass-Micon B. Painful supernumerary phantom arm following motor cortex stimulation for central poststroke pain. J Neurosurg 1999;91:121-123.

22. Yamamoto T, Katayama Y, Hirayama T, et al. Pharmacological classification of central post-stroke pain: comparison with the results of chronic motor cortex stimulation therapy. Pain 1997;72:5-12.

23. Migita K, Uozumi T, Arita K, Monden S. Transcranial magnetic coil stimulation of motor cortex in patients with central pain. Neurosurgery 1995;36: 1037-1041.

24. Bezard E, Boraud T, Nguyen JP, Velasco F, Keravel Y, Gross C. Cortical stimulation and epileptic seizure: a study of the potential risk in primates. Neurosurgery 1999;45:346-350

25. Franzini A, Ferroli P, Servello D, Broggi G. Reversal of thalamic hand syndrome by long-term motor cortex stimulation: case report. J Neurosurg 2000:93:873-875

26. Blond S, Touzet G, Reyns N, et al. Les Techniques de neurostimulation dans le traitement de la douleur chronique. Neurochirurgie 2000;46:466-482. 